Provided for non-commercial research and education use. Not for reproduction, distribution or commercial use.

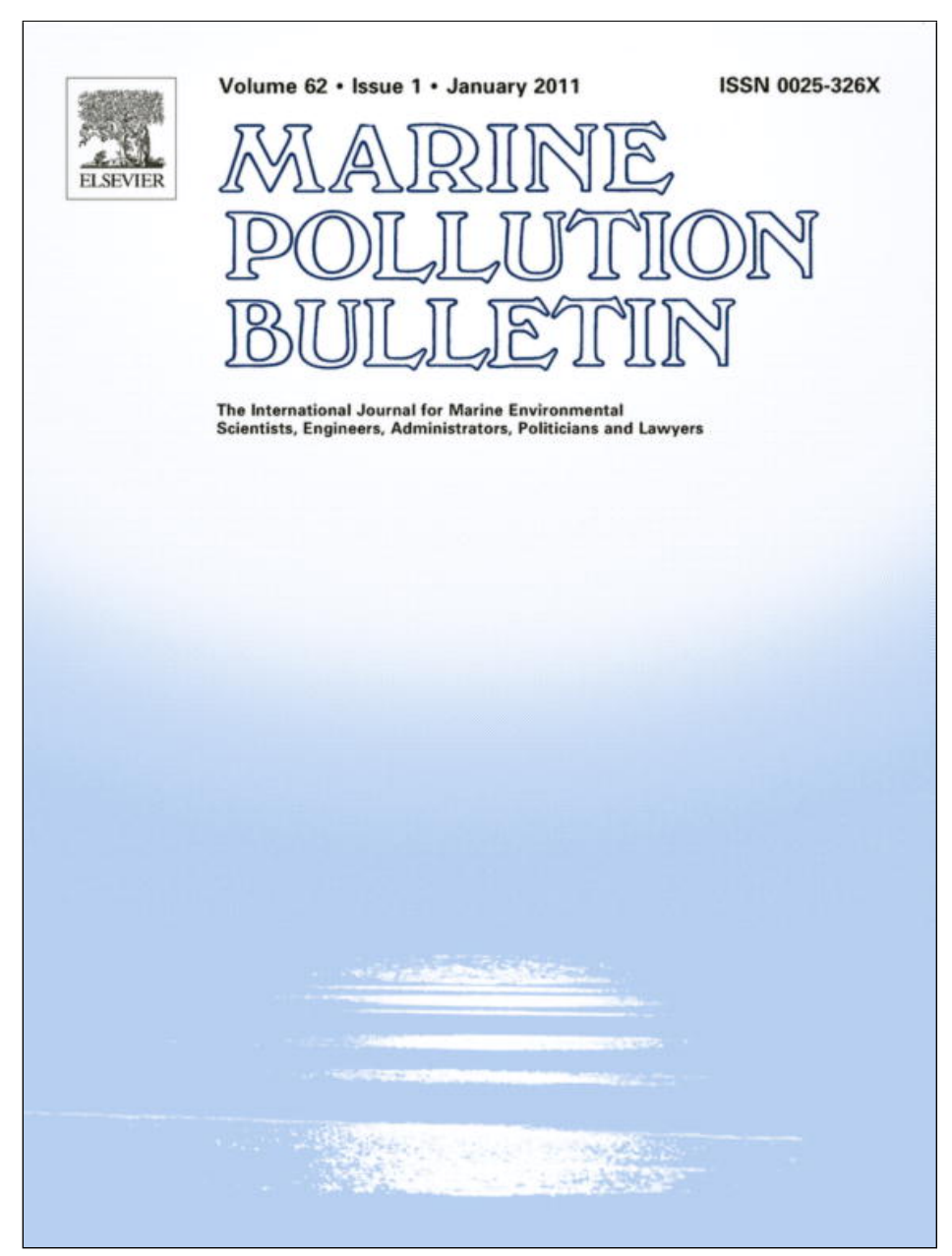

This article appeared in a journal published by Elsevier. The attached copy is furnished to the author for internal non-commercial research and education use, including for instruction at the authors institution and sharing with colleagues.

Other uses, including reproduction and distribution, or selling or licensing copies, or posting to personal, institutional or third party websites are prohibited.

In most cases authors are permitted to post their version of the article (e.g. in Word or Tex form) to their personal website or institutional repository. Authors requiring further information regarding Elsevier's archiving and manuscript policies are encouraged to visit:

http://www.elsevier.com/copyright 


\title{
Estuarine ecological risk based on hepatic histopathological indices from laboratory and in situ tested fish
}

\author{
Pedro M. Costa ${ }^{\mathrm{a}, *}$, Sandra Caeiro ${ }^{\mathrm{a}, \mathrm{b}}$, Jorge Lobo $^{\mathrm{a}}$, Marta Martins ${ }^{\mathrm{c}}$, Ana M. Ferreira ${ }^{\mathrm{c}}$, Miguel Caetano $^{\mathrm{c}}$, \\ Carlos Vale ${ }^{\mathrm{c}}$, T. Ángel DelValls ${ }^{\mathrm{d}}$, Maria H. Costa ${ }^{\mathrm{a}}$ \\ ${ }^{a}$ IMAR-Instituto do Mar, Departamento de Ciências e Engenharia do Ambiente, Faculdade de Ciências e Tecnologia da Universidade Nova de Lisboa, 2829-516 Caparica, Portugal \\ ${ }^{\mathrm{b}}$ Departamento de Ciências e Tecnologia, Universidade Aberta, Rua da Escola Politécnica, 141, 1269-001 Lisboa, Portugal \\ ${ }^{\mathrm{c}}$ IPIMAR-INRB, Instituto Nacional dos Recursos Biológicos, Avenida de Brasília, 1449-006 Lisboa, Portugal \\ d UNESCO/UNITWIN/WiCop Chair-Departamento de Química Física, Facultad de Ciencias del Mar y Ambientales, Universidad de Cádiz, Polígono río San Pedro s/n, 11510 Puerto Real, \\ Cádiz, Spain
}

\section{A R T I C L E I N F O}

\section{Keywords:}

Solea senegalensis

Histopathology

Weighted indices

Contaminated sediments

Estuary

Bioassays

\begin{abstract}
A B S T R A C T
Juvenile Senegalese soles were exposed through 28-day laboratory and field (in situ) bioassays to sediments from three sites of the Sado estuary (W Portugal): a reference and two contaminated by metallic and organic contaminants. Fish were surveyed for ten hepatic histopathological alterations divided by four distinct reaction patterns and integrated through the estimation of individual histopathological condition indices. Fish exposed to contaminated sediments sustained more damage, with especial respect to regressive changes like necrosis. However, differences were observed between laboratory- and fieldexposed animals, with the latest, for instance, exhibiting more pronounced fatty degeneration and hepatocellular eosinophilic alteration. Also, some lesions in fish exposed to the reference sediment indicate that in both assays unaccounted variables produced experimental background noise, such as hyaline degeneration in laboratory-exposed fish. Still, the field assays yielded results that were found to better reflect the overall levels of contaminants and physico-chemical characteristics of the tested sediments. (c) 2010 Elsevier Ltd. All rights reserved.
\end{abstract}

\section{Introduction}

The determination of the ecological risk of contaminated sediments has long been recognized as a key issue to assess the effects of anthropogenic pressure onto the natural environments, in this case, the release of pollutants to aquatic ecosystems. Aquatic sediments and, in particular, estuarine sediments, are complex media with respect to physical, chemical and biological characteristics that trap, store, modify and, under certain circumstances, release contaminants to the biota. For all these reasons, integrative, "holistic", approaches have been attempted to evaluate sediment ecological risk, combining sediment geochemistry, biotic composition and diversity and, among other potential lines-of-evidence, the effects of sediment-bound contaminants to aquatic organisms (Chapman and Hollert, 2006).

Due to its complex nature, the evaluation of sediment risk for biomonitoring, regulatory, or more baseline ecological and toxicological purposes (including the analysis of toxic effects to organisms), has been given particular attention. Although many studies focused on feral animals, bioassays are widely employed in ecotoxicological studies. Still, performing bioassays with natural

\footnotetext{
* Corresponding author. Tel.: +351 212948 300x10103; fax: +351 212948554 .

E-mail address: pmcosta@fct.unl.pt (P.M. Costa).
}

sediments has many constraints, from the presence of contaminant mixtures (that may result in antagonistic or additive effects that mask the outcomes of individual contaminants) to the factors that affect bioavailability, as well as the often unpredictable environmental variables that cause experimental noise. The choice between laboratory and in situ (field) assays thus relies on the balance between the need to reduce the background noise of the experiment with the least compromise of ecologically relevant results. Few studies have, however, focused on the differences between laboratory and in situ assays and each type's assets and disadvantages (as, for instance, Vethaak et al., 1996; Hatch and Burton, 1999) and none were found comparing directly the histopathological results obtained from the two approaches even though Riba et al. (2005) found similar types and levels of lesions in Senegalese soles exposed to contaminated sediments from proximate areas in the laboratory and in situ, although the fish were not tested simultaneously. Still, some authors have discussed that the two types of bioassays are adequate for biomonitoring procedures in spite of differences in the toxicity effects to organisms (Hatch and Burton, 1999; Riba et al., 2005).

The employment of histopathological biomarkers to determine the effects of environmental contamination has been perceived as a highly relevant methodology since they reflect the true health state of the organism. With respect to aquatic environments, the 
fish liver has been considered one of the major targets of assessment due to its function in xenobiotic transformation, storage and, even, elimination, with the gills, kidneys, gonads and digestive tract being other common subjects (see Bernet et al., 1999; Wester et al., 2002; Au, 2004, for a review). Assessing hepatic histopathology in feral fish is long surveyed for biomonitoring and regulatory purposes. Among these studies, the survey of neoplasic or pre-neoplasic lesions in benthic fish, especially flatfish, is recurrent (e.g. Myers et al., 1998; Koehler, 2004; Lang et al., 2006).

If the importance of purely qualitative approaches to histopathology cannot be disregarded since it allows the detection and development of new potential biomarkers as well as the biological significance of the lesions and alterations (e.g. Köhler, 1990; Costa et al., 2010), semi-quantitative approaches are needed when it is intended to integrate biological data with environmental parameters through, e.g., multivariate statistics, in order to search for cause-effect relationships. Still, if these approaches are widespread concerning other classes of biomarkers, obtaining figures for histopathological traits is not yet a rule. This results mostly from (i) the difficulties of objectively identifying histological changes; (ii) the frequent lack of consensus between terminology and even identification of histopathological features; (iii) the many gaps that remain about the biological significance of the lesions or alterations to tissue and organs and (iv) the lack of important cause-effect information which, combined with the potential unspecific profile of histological changes, makes it difficult to discriminate between the real effects or responses and experimental noise. It should be noted that although much information exists in the fields of biomedicine, histopathology data on fish is scarce and even scarcer on aquatic invertebrates, although such subject is out-of-scope of the present work.

Different attempts have been made to semi-quantify histopathological features in fish exposed to xenobiotics. Some authors developed tissue quality indices that are attributed to sites or treatments, e.g., by attributing an arbitrary degree of dissemination of one or more alterations within a given population (see for instance DelValls et al., 1998; Riba et al., 2005; Lang et al., 2006; Oliva et al., 2009). However, the development of individual indices is gaining interest. Among these, weighted indices are of especial relevance since they are based on the premise that the histological changes may not have the same impact (biological significance) to the animal. By attributing a numerical value to the relative importance (weight) of the alteration plus a dissemination factor, an histopathological condition indice can be obtained for each individual (Bernet et al., 1999; Costa et al., 2009b).

The Senegalese sole (Solea senegalensis Kaup, 1858; Pleuronectiformes: Soleidae) is a common flatfish in the Iberian Peninsula. It is a benthic fish that is often found in estuaries, preferring sandymuddy bottoms where it feeds on small invertebrates (Cabral, 2000). The species is of ecological and economical importance in the study area of the present work, the Sado estuary (Portugal, W Europe) and also an important aquaculture species in Southern Europe and the Mediterranean. Several ecotoxicological studies based on bioassays with the Senegalese sole have arisen in the past few years, taking advantage of the availability of the fish from aquaculture facilities and its benthic behaviour. These include laboratory exposure to waterborne or directly injected contaminants (Arellano et al., 1999; Prieto-Álamo et al., 2009; Oliva et al., 2009) and contaminated sediments (Riba et al., 2004, 2005; Salamanca et al., 2008; Costa et al., 2008, 2009a,b, 2010). The rising number of ecotoxicological studies with the species may indicate that $S$. senegalensis can achieve the potential in SW Europe that Platichthys flesus has been recognized with in the northwest for the environmental monitoring of marine and estuarine sediments. Still, much research is missing regarding the testing and validation of biomarkers and other indicators of aquatic pollution. Among the var- ious responses and effects surveyed during these exposures, histopathological changes have also been evaluated (Arellano et al., 1999; Riba et al., 2005; Salamanca et al., 2008; Oliva et al., 2009; Costa et al., 2009b, 2010). Previous studies from our group showed that laboratory tests may enhance toxicity by increasing the bioavailability of the contaminants trapped in the sediments likely through the combination of fish- and sediment handling-driven resuspension and the sediments' physico-chemical properties like redox potential and organic matter, with consequences to the histopathological evaluation (Costa et al., 2009b, 2010). These findings led to the design of a new series of bioassays, performed simultaneously in the laboratory and in the field, using the same species and considering the same locations.

The present work aims to (1) identify histological lesions and alterations in the liver of $S$. senegalensis exposed to contaminated sediments and semi-quantify the results through histopathological weighted indices; (2) compare the results between laboratory- and in situ-exposed animals to the same sediments in order to infer the advantages and handicaps of each type of assay as well as to determine potential confounding factors and (3) contrast the histopathological results to the sediments' characterization data to determine which histological biomarkers more effectively reflect the levels of contaminants, factors potentially affecting bioavailability and the effects of xenobiotic interactions.

\section{Methods and materials}

\subsection{Study area}

The Sado estuary (W Portugal) is a large basin of great ecological, social and economical importance. The estuary is historically subjected to many sorts of anthropogenic usage and alteration and includes a large city (Setúbal, with an important commercial harbour) and a dense agglomerate of heavy-industry (including chemical plants, a paper mill, a large thermoelectrical unit, shipyards and ore deployment facilities). It is also important for fisheries, tourism and aquaculture activities and a large portion of the estuary is classified as a natural reserve (Fig. 1). Three sites of the estuary were chosen according to previous research (Caeiro et al., 2005; Neuparth et al., 2005; Costa et al., 2009a). The reference site $(R)$, located off the Tróia Peninsula, is the farthest from direct pollution sources (by more than three $\mathrm{km}$ ). Sites $C_{1}$ and $C_{2}$ were considered the contaminated sites, although with different physico-chemical characteristics and levels of metallic and organic contaminants. They are located near Setúbal's harbour and off the city's heavy-industry belt, respectively.

\subsection{Bioassays}

Sediments samples from the three sites (Fig. 1), for contaminant analyses and the laboratory assays, were collected with a Petite Ponar grab on May 2007. Juvenile laboratory hatched and reared Senegalese soles (standard length $=61.0 \pm 8.4 \mathrm{~mm}$; total wet weight $=3.1 \pm 1.6 \mathrm{~g}$ ), all from the same cohort, were used as test subjects. To simplify, exposures to sediments from sites $R$ (reference) and $C_{1}$ and $C_{2}$ (contaminated) will throughout be referred to as tests $R, C_{1}$ and $C_{2}$.

The in situ (field) assays were set in the same areas where the sediments were collected. Submerged cages were placed over the bottom (ensuring direct contact with the sediment) by scuba diving (at 7-10 m depth). The cages consisted of $90 \times 90 \times 30 \mathrm{~cm}$ PVC plastic structures lined with a $5 \mathrm{~mm}$ plastic mesh. Each cage was divided in two equal-sized compartments (replicates), each allocating twenty randomly-selected animals. The laboratory assay was prepared according to previous research (Costa et al., 2009b). 


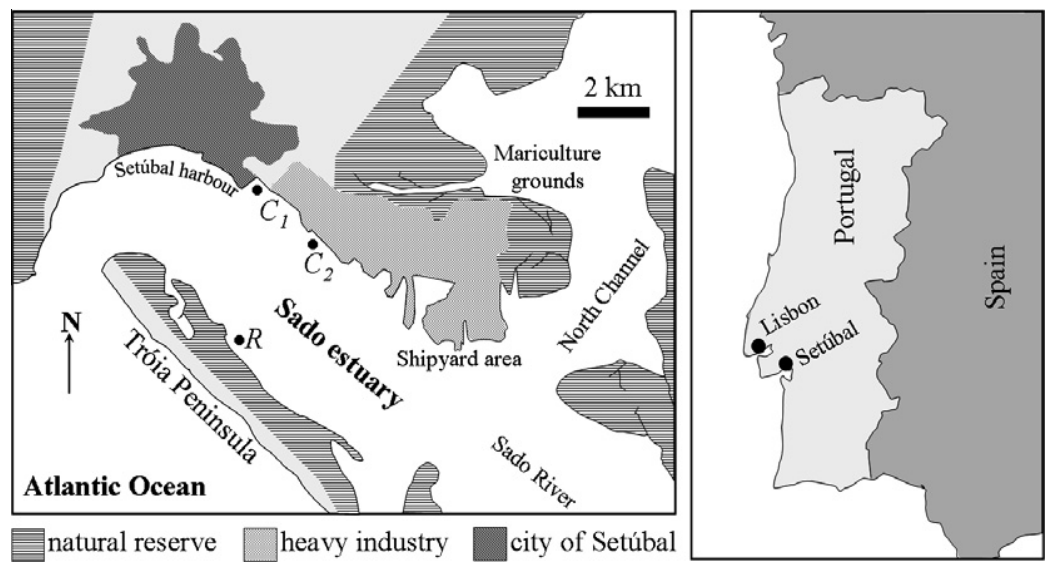

Fig. 1. Map of the Sado estuary (W Portugal) with the location of the assay and sediment collection sites $R$ (reference) and $C_{1}$ and $C_{2}$ (contaminated).

In brief: $2 \mathrm{~L}$ of freshly-collected sediments were placed in $15 \mathrm{~L}-$ capacity white polyvinyl tanks with blunt edges to which was added $10 \mathrm{~L}$ of clean, $0.45 \mu \mathrm{m}$-filtered, seawater. Sediments (total surface $\approx 525 \mathrm{~cm}^{2}$ ) were allowed to settle for $48 \mathrm{~h}$ before the beginning of the assay. The test tanks were equipped with a recirculation system and constant aeration, with water and air flows set to avoid sediment disturbance. The assays were performed in duplicate, with twenty randomly-selected animals being placed in each tank. A weekly $25 \%$ water change was done to maintain constancy of parameters with minimal removal of suspended particles and contaminants. Temperature was held constant as $18 \pm 1{ }^{\circ} \mathrm{C}$ and the photoperiod was set at $12: 12 \mathrm{~h}$ light:dark. Water parameters were monitored weekly and were similar to the animals' rearing conditions: salinity $=32.1 \pm 0.3, \mathrm{pH}=8.0 \pm 0.1$, dissolved oxygen $=56.5 \pm 0.2 \%$ and unionized ammonia $\left(\mathrm{NH}_{3}\right)$ was restrained within $0.04 \pm 0.02 \mathrm{mg} \mathrm{L}^{-1}$. Fish were fed daily with commercial pellets.

Field and laboratory assays were run simultaneously and had the duration of 28 days. Sampling was scheduled for days $0\left(\mathrm{~T}_{0}\right)$, $14\left(\mathrm{~T}_{14}\right)$ and $28\left(\mathrm{~T}_{28}\right)$ of the experiment. At $\mathrm{T}_{14}$ and $\mathrm{T}_{28}$ three to five animals per replica were collected from each cage or tank and measured for total wet weight $\left(w w_{\mathrm{t}}\right)$ and standard length $\left(L_{\mathrm{s}}\right)$ before processing. Fish were then euthanized by cervical sectioning and liver portions were excised and prepared for subsequent histological analysis. $\mathrm{T}_{0}$ fish consisted of ten animals collected from the rearing tanks.

\subsection{Sediment characterization}

Sediment redox potential (Eh) was measured immediately after collection using an Orion 20A apparatus equipped with a H3131 platinum electrode with an $\mathrm{Ag} / \mathrm{AgCl}$ reference electrode. Sediment total organic matter (TOM) was inferred from organic carbon losson-ignition after sample heating at $500^{\circ} \mathrm{C}$ for $5 \mathrm{~h}$. Fine fraction (FF), particle size $<63 \mu \mathrm{m}$, was determined by hydraulic sieving following disaggregation with pyrophosphate.

Sediment element contaminants, the non-metal selenium (Se); the metalloid arsenic (As) and the metals cadmium (Cd), cobalt (Co), chromium $(\mathrm{Cr})$, copper $(\mathrm{Cu})$, manganese $(\mathrm{Mn})$, nickel $(\mathrm{Ni})$, lead $(\mathrm{Pb})$ and zinc $(\mathrm{Zn})$, were determined from dried sediment samples by inductively coupled plasma mass spectrometry (ICP-MS) using a Thermo Elemental X-Series equipment, after mineralization with acids $\left(\mathrm{HCl}, \mathrm{HNO}_{3}\right.$ and $\left.\mathrm{HF}\right)$ in Teflon vials according to Caetano et al. (2007). Total mercury (Hg) was determined from dried sediment samples by atomic absorption spectrometry (AAS) according to Costley et al. (2000), after pyrolysis of the samples at $750^{\circ} \mathrm{C}$ in an oxygen atmosphere in a combustion tube attached to an
AMA-254 mercury analyzer (Leco). The reference sediments MESS-2and PACS-2 (National Research Council, Canada) and MAG-1 (US Geological Survey, USA) were analyzed by the same protocols to validate the procedure and the values were found within the certified range.

Sediment PAHs were determined from dried samples spiked with surrogate standards (from Supelco) by gas chromatography-mass spectrometry (GC-MS) as described by Martins et al. (2008), after Soxhlet-extraction with an acetone + hexane mixture, using a Finnigan GCQ system. Seventeen 3- to 6-ring PAHs were quantified. Organochlorines (18 PCB congeners and DDTs, namely $p p^{\prime} \mathrm{DDT}$ plus the $p p^{\prime} \mathrm{DDD}$ and $p p^{\prime} \mathrm{DDE}$ metabolites) were quantified by GC-MS from dried sediment samples following Soxhlet-extraction with $n$-hexane and fractioning in a chromatographic column according to Ferreira et al. (2003), using a Hewlett-Packard 6890 apparatus. Validation was achieved by analysis of the SRM 1941b reference sediment (National Institute of Standards and Technology, USA) and the obtained values were found within the certified range.

\subsection{Histopathological analyses}

Liver portions were fixed in Bouin-Hollande's solution $(10 \% \mathrm{v} / \mathrm{v}$ formaldehyde and $7 \% \mathrm{v} / \mathrm{v}$ acetic acid to which picric acid was added till saturation) for $36 \mathrm{~h}$ at room temperature, washed in distilled water $\mathrm{o} / \mathrm{n}$, dehydrated in a progressive series of ethanol and embedded in paraffin (xylene was employed for intermediate impregnation). Sections ( $2-3 \mu \mathrm{m}$ thick) were stained with haematoxylin and counterstained with alcoholic eosin (H\&E). The procedure follows essentially Martoja and Martoja (1967). Other staining techniques were used to confirm the identification or highlight specific structures, namely: Sudan Black B for the histochemistry of protein-bound lipids in paraffin sections (prepared according to Bronner, 1975); Coomassie Brilliant Blue R250 (CBB) for the histochemical detection of protein (Fisher, 1968) and the Giemsa stain (in pH 4.8-5.8 phosphate-buffered saline) to aid identification of active Kupfer cells (after Kiernan, 2008). The slides were prepared in duplicate per sample (each containing eight to twelve sequential sections) and were mounted with DPX resin. All analyses were carried out using a DMLB model microscope (Leica Microsystems).

A semi-quantitative approach was enforced, based on the weighted histopathological condition indices proposed by Bernet et al. (1999). The estimation of the hepatic histopathological condition $\left(I_{\mathrm{h}}\right)$ indices is based on the concepts of: (1) each lesion or alteration's relative biological importance (weight) and (2) the score value, a numerical attribute that reflects the degree of dissemina- 
tion of the alteration within the surveyed organ. The indices are obtained for each individual and the histopathological alterations are divided by four reactions patterns, as defined by Bernet and co-workers: (1) circulatory disturbances; (2) inflammatory response; (3) regressive alterations and (4) progressive alterations. The $I_{\mathrm{h}}$ indice for each fish is computed as:

$I_{\mathrm{h}}=\sum_{i=1}^{4} I_{i}$

where $I_{i}$ is the condition indice for the $i$ th reaction pattern (1-4), which is calculated by the formula:

$I_{\mathrm{i}}=\sum_{j=1}^{x} w_{j} a_{j}$

where $j$ represents the $j$ th lesion or alteration within each reaction pattern $i$ and $w_{j}$ and $a_{j}$ the weight and score, respectively, for the $j$ th alteration. As defined by Bernet and co-workers, the score can attain the values of 0 (unaltered condition or unobserved lesion), 2 (infrequent occurrence); 4 (moderate occurrence) or 6 (severely disseminated/diffuse). A series of blind reviews of slides was employed to confirm the accuracy of observations.

\subsection{Statistical analyses}

Test statistics were performed on the individual $I_{\mathrm{h}}$ and $I_{i}$ indices. Failure to meet the homogeneity of variances and/or the normality assumptions for parametric analysis of variance (given by the Levene and Kolmogoroff-Smirnoff tests, respectively), led to the employment of the non-parametric Mann-Whitney $U$ test to determine pairwise differences between $I_{\mathrm{h}}$ values. Cluster analysis based on the 1-Pearson correlation $r$ statistic was used to investi- gate links between the $I_{j}$ values (weight $\times$ score) for the different histopathological traits observed. Discriminant analysis was used to determine the relative significance of each reaction pattern in the distinction between assay type and sampling time. The significance level was set at $\alpha=0.05$ for all analyses. Statistics were obtained using Statistica (Statsoft Inc.).

\section{Results}

Distinct levels of aggregate mortality (after the 28 days of exposure) were observed between the laboratory and the field assays. In the laboratory experiment, exposure to sediment $C_{2}$ caused the highest ( 14 out of 40 individuals), followed by exposure to sediment $R$ and $C_{1}$ (with 7 and 5 animals of 40 , respectively). Unexpectedly, exposure to sediment $R$ (the reference sediment) in the field was responsible for a comparatively high mortality (13/40) while only 5 of 40 fish were lost during both tests $C_{1}$ and $C_{2}$.

\subsection{Sediment characterization}

The sediments from the three sites revealed distinct physicochemical properties and levels of contamination. The sediments from the reference site (site $R$ ) were found the least contaminated for both inorganic and organic contaminants, as well as the least anoxic and with the lowest percentage of fine grained particles and total organic matter (Table 1 ). Sediment from site $C_{1}$ was the most contaminated by metals, As and Se, whereas sediment from site $C_{2}$ was the most contaminated by organic xenobiotics, (PAHs and organochlorines), although the PAH levels were close to those of sediment $C_{1}$. Organochlorines were virtually absent from the reference sediment. The two contaminated sediments were found to be very anoxic and holding a high content of organic matter (high-

Table 1

Physico-chemical characterization of the sediments collected from the surveyed sites $R$ (reference) and $C_{1}$ and $C_{2}$ (contaminated). Ranges indicate the quantification error.

\begin{tabular}{|c|c|c|c|c|c|}
\hline & & & \multicolumn{3}{|l|}{ Site } \\
\hline & & & $R$ & $C_{1}$ & $C_{2}$ \\
\hline & \multicolumn{2}{|l|}{ Eh $(\mathrm{mV})$} & -140 & -300 & -312 \\
\hline & \multicolumn{2}{|l|}{ TOM (\%) } & 22.53 & 95.64 & 75.84 \\
\hline & \multicolumn{2}{|l|}{$\mathrm{FF}(\%)$} & 2.25 & 10.19 & 7.22 \\
\hline \multirow[t]{11}{*}{ Element ( $\mu \mathrm{g} \mathrm{g}^{-1}$ sediment $\left.\mathrm{dw}\right)$} & Non-metal & Se & $0.27 \pm 0.01$ & $1.21 \pm 0.02$ & $0.80 \pm 0.02$ \\
\hline & Metalloid & As & $5.20 \pm 0.10$ & $23.98 \pm 0.48$ & $20.69 \pm 0.41$ \\
\hline & \multirow[t]{9}{*}{ Metal } & $\mathrm{Cd}$ & $0.06 \pm 0.00$ & $0.26 \pm 0.01$ & $0.29 \pm 0.01$ \\
\hline & & Co & $3.37 \pm 0.07$ & $13.94 \pm 0.28$ & $9.43 \pm 0.19$ \\
\hline & & $\mathrm{Cr}$ & $18.14 \pm 0.36$ & $80.73 \pm 1.61$ & $51.70 \pm 1.03$ \\
\hline & & $\mathrm{Cu}$ & $28.20 \pm 0.56$ & $172.72 \pm 3.45$ & $95.31 \pm 1.91$ \\
\hline & & $\mathrm{Hg}$ & $0.11 \pm 0.00$ & $0.69 \pm 0.01$ & $0.71 \pm 0.01$ \\
\hline & & Mn & $100.75 \pm 2.01$ & $464.34 \pm 9.29$ & $362.47 \pm 7.25$ \\
\hline & & $\mathrm{Ni}$ & $7.31 \pm 0.15$ & $33.30 \pm 0.67$ & $20.49 \pm 0.41$ \\
\hline & & $\mathrm{Pb}$ & $18.57 \pm 0.37$ & $55.19 \pm 1.10$ & $43.76 \pm 0.88$ \\
\hline & & $\mathrm{Zn}$ & $72.29 \pm 1.45$ & $364.83 \pm 7.30$ & $269.31 \pm 5.39$ \\
\hline \multirow[t]{15}{*}{ Organic contaminant ( $\mathrm{ng} \mathrm{g}^{-1}$ sediment dw) } & \multirow[t]{4}{*}{$\mathrm{PAH}$} & 3-ring & $15.29 \pm 2.45$ & $114.83 \pm 18.37$ & $100.70 \pm 16.11$ \\
\hline & & 4-ring & $50.90 \pm 8.14$ & $701.19 \pm 112.19$ & $772.24 \pm 123.56$ \\
\hline & & 5 -ring & $26.65 \pm 4.26$ & $415.18 \pm 66.43$ & $423.92 \pm 67.83$ \\
\hline & & 6-ring & $8.97 \pm 1.43$ & $133.99 \pm 21.44$ & $150.85 \pm 24.14$ \\
\hline & \multirow{6}{*}{$\begin{array}{l}\text { PAH } \\
\text { PCB }\end{array}$} & & $101.80 \pm 16.29$ & $1365.20 \pm 218.43$ & $1447.71 \pm 231.63$ \\
\hline & & Trichlorinated & $0.05 \pm 0.01$ & $2.33 \pm 0.37$ & $2.75 \pm 0.44$ \\
\hline & & Tetrachlorinated & $0.03 \pm 0.01$ & $0.40 \pm 0.06$ & $1.08 \pm 0.17$ \\
\hline & & Pentachlorinated & $0.03 \pm 0.01$ & $1.06 \pm 0.17$ & $1.61 \pm 0.26$ \\
\hline & & Hexachlorinated & $0.41 \pm 0.07$ & $2.77 \pm 0.44$ & $4.29 \pm 0.69$ \\
\hline & & Heptachlorinated & $0.27 \pm 0.04$ & $1.34 \pm 0.21$ & $2.24 \pm 0.36$ \\
\hline & $t P C B$ & & $0.80 \pm 0.13$ & $7.91 \pm 1.26$ & $11.97 \pm 1.92$ \\
\hline & \multirow[t]{3}{*}{ DDT } & $p p$ 'DDD & $<$ d.l. & $0.37 \pm 0.01$ & $0.71 \pm 0.01$ \\
\hline & & $p p ' \mathrm{DDE}$ & $<$ d.l. & $<$ d.1. & $0.59 \pm 0.01$ \\
\hline & & $p p$ 'DDT & $<$ d.l. & $<$ d.l. & $1.22 \pm 0.02$ \\
\hline & \multicolumn{2}{|l|}{$t D D T$} & - & $0.37 \pm 0.01$ & $2.52 \pm 0.05$ \\
\hline
\end{tabular}

$<$ d.l. - below detection limit; DDT - dichloro diphenyl trichloroethane; Eh - redox potential; FF - fine fraction (particle size < 63 um); PAH - polycyclic aromatic hydrocarbon PCB - polychlorinated biphenyl; TOM - total organic matter. 
est for $C_{1}$ ). Four- and five-ring compounds represent $\approx 75-80 \%$ of all surveyed PAHs contamination in all sediments, the best represented being fluoranthene and pyrene with concentrations of 315.7 and $263.2 \mathrm{ng} \mathrm{g}^{-1}$ sediment $\mathrm{dw}$ in sediment $C_{1}$, respectively, and 345.2 and $286.3 \mathrm{ng} \mathrm{g}^{-1}$ sediment dw for $C_{2}$. Hexachlorinated PCBs were the most representative PCBs in all sediments, with the highest value being found in sediment $C_{2}$ (4.29 $\mathrm{ng} \mathrm{g}^{-1}$ sediment dw).

\subsection{Liver histopathology}

Typically, fish collected at the beginning of the experiment $\left(\mathrm{T}_{0}\right)$ presented the normal hepatic architecture consistent with juveniles, showing regular hepatocytes, more or less polyedric in shape, with a clear cytoplasm, which should indicate good glycogen storage as previously described for the species (Costa et al., 2009b), and regular-sized nuclei with conspicuous nucleoli. At high-power magnifications, eu- and heterochromatin are clearly discernible. Many sinusoids could be observed branching out of larger blood vessels where a few blood cells (mostly erythrocytes) could be observed (Fig. 2A). The occurrence of lesions in the livers of $T_{0}$ fish was, in general, low.

Exposure to contaminated sediments, $C_{1}$ and $C_{2}$, globally caused the most pronounced alterations to the hepatic parenchyma. However, laboratory- and field-exposed fish depicted distinct patterns and levels of histopathological changes, most obvious in animals sampled after fourteen days of exposure, since at $\mathrm{T}_{14}$ the livers of field-tested animals sustained the greater damage, especially in fish exposed to sediment $C_{1}$, contaminated by both element and organic xenobiotics. After 28 days, the exposure to all sediments, including to the reference sediment $(R)$, was responsible for increased alterations to the hepatic parenchyma when compared to $\mathrm{T}_{0}$ animals, even tough fish exposed to sediments $C_{1}$ and $C_{2}$ sustained greater damage in both type of assays, more notoriously for in situ-exposed animals.

Amongst the alterations most often observed in the livers of fish exposed to the two most contaminated sediments $\left(C_{1}\right.$ and $\left.C_{2}\right)$; both in the laboratory and in situ (Fig. 2B-F), circulatory disturbances and inflammatory response-related alterations were some of the most conspicuous. Haemorrhages were frequently observed around blood vessels, especially when blood-swollen vessels (leading to blood stasis) and proliferation of sinusoids indicated some degree of inflammatory response (Fig. 2B and E). Erythrocytes from ruptured vessels were often observed to intrude into foci of necrotic tissue spreading from the periportal area ("piecemeal" necrosis). Necrotic foci were present in fish subjected to all treatments and $\mathrm{T}_{0}$ fish. Although the extension and relative number of these foci were variable, fish exposed to sediments $C_{1}$ and $C_{2}$ sustained necrosis more diffusively, both in the laboratory and in situ, while in most animals exposed to the reference sediment (and $\mathrm{T}_{0}$ fish), necrosis was either absent or constricted to small foci, usually around the periportal area. The most severe necrosis was observed in the livers of laboratory-tested fish exposed to sediment $C_{1}$ (contaminated by metallic and organic substances), collected at both $\mathrm{T}_{14}$ and $\mathrm{T}_{28}$, with necrotic areas being found disseminated throughout the entire organ and not just circumscribed to the periportal region. The most necrotic livers typically presented changes in the bile duct structure, exhibiting tubular structural regression and/or necrotic epithelia (Fig. 2B). Necrotic hepatocytes usually presented nuclear pleomorphisms, such as pyknosis or hypertrophy. Some evidence of apoptosis, revealed by changes in chromatin structure, was observed in the most damaged livers (Fig. 2C).

Altered hepatocytes (eosinophilic hepatocellular alteration) and lipidosis ("fat" degeneration) were found to be common alterations in fish subjected to all tests, with a variable degree of dissemination. Still, these alterations were more diffuse in field-exposed ani- mals, including in fish tested in the reference site $(R)$ for 28 days. No evidence for microvesicular fat degeneration (steatosis) was found. Altered hepatocytes typically presented more eosinophilic (acidophilic) cytoplasms' (thus retaining much eosin, an acidic reddish pigment), accompanied by an alteration in shape and size, loosing their common polyedric outline and frequently presenting hypertrophy (Fig. 2C-E). Although eosinophilic hepatocellular alteration is considered a pre-neoplasic lesion (Koehler et al., 2004), no evidence was found for the presence of benign or malignant tumours in the livers of surveyed animals. Fat vacuoles could often be found inside altered hepatocytes, with the largest and most numerous being observed in field-exposed fish for 28 days. The most damaged livers frequently presented a combination of severe progressive and regressive changes (like necrosis and eosinophilic hepatocellular alteration, respectively). In these cases, Kupfer cells (liver-specialized macrophages) were often observed intruding into the damaged tissue (Fig. 2D and F), whereas melanomacrophages were more frequently observed in the periportal areas, occasionally forming dense centres (Fig. 2C).

The presence of various small intraplasmatic eosinophilic bodies (appearing as reddish circular or oval structures) inside hepatocytes was common in animals exposed to the two most contaminated sediments in both types of assays (hyaline degeneration). However, fish exposed in the laboratory to the reference sediment presented large, few or single, eosinophilic bodies that compressed the nucleus and cytoplasm against the plasmatic membrane (Fig. 2G). Laboratory-tested animals exposed to sediment $R$ presented more diffuse hyaline degeneration (and larger eosinophilic bodies) than $T_{14}$ fish. Still, the overall structural aspect of the hepatic parenchyma did not appear compromised, with little or no evidence for necrosis or eosinophilic hepatocellular alteration. These inclusions presented a clear halo and were strongly stained by eosin. Staining with Sudan Black yielded positive for protein-bound lipids inside eosinophilic bodies (Fig. 2H), as well as for total protein through Coomassie Blue staining (Fig. 2I). Neither staining was observed to be homogenous, revealing the coexistence of different sorts of undetermined material inside the inclusions. Hyaline degeneration was not, nevertheless, observed in field-tested fish exposed to sediment $R$.

\subsection{Hepatic histopathological condition indices}

The list of surveyed pathologies was determined from preliminary observations. Four reaction patterns were considered, each comprising one of several histopathological lesions or alterations to which was attributed its respective condition weight (Table 2). The weights $(w)$ were attributed according to previous research (Bernet et al., 1999; Costa et al., 2009b). Circulatory disturbances and inflammatory response-related alterations (except Kupfer cell infiltration with $w=2$ ) and lipidosis were attributed the lowest weights $(w=1)$ whereas necrosis was given the highest $(w=3)$. Nuclear pleomorphisms and bile duct structural changes received the intermediate value of $w=2$, as well as hyaline degeneration and hepatocellular eosinophilic alteration, the latest being generally regarded as a pre-neoplasic alteration.

With the exception of animals exposed to the reference sediment for 14 days, either in the laboratory or in situ, all tests caused an increase in the hepatic histopathological indice $I_{\mathrm{h}}[1]$ relatively to $\mathrm{T}_{0}$ animals, indicating that the fish were enduring lesions and alterations in the hepatic parenchyma throughout the assays (Fig. 3). Laboratory- and field-tested fish depicted distinct patterns of hepatic histopathological changes. Field-exposed animals to sediments $C_{1}$ and $C_{2}$ for fourteen days had $I_{\mathrm{h}}$ values significantly higher than laboratory-exposed fish to the same sediments. Also, exposures to sediments $C_{1}$ and $C_{2}$ resulted in higher indices than exposure to the reference sediment for both types of assays at 

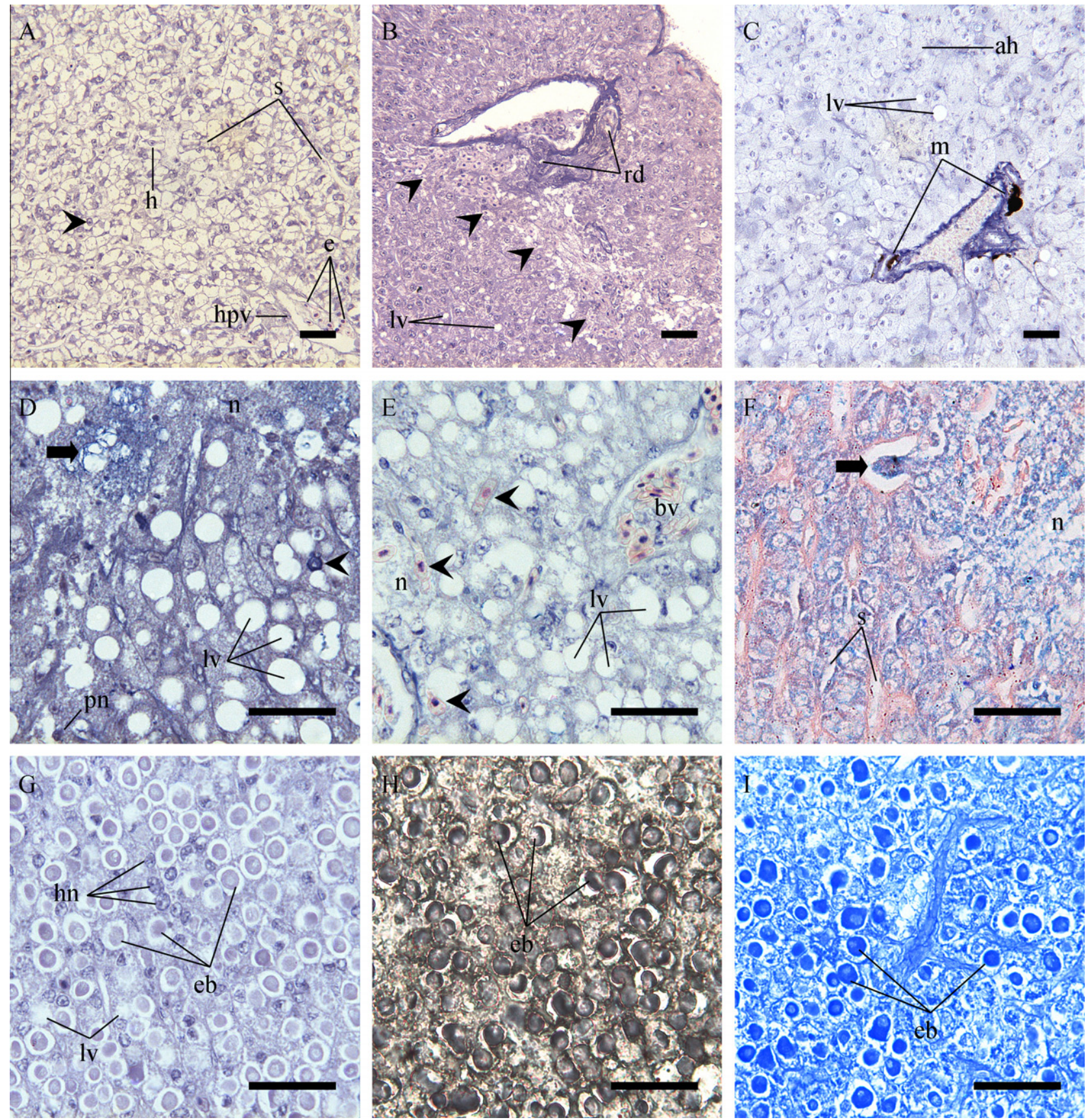

Fig. 2. Common histopathological lesions and alterations observed in the livers of laboratory and in situ-exposed soles. Scale bar: $25 \mu \mathrm{m}$. (A) Overall aspect of the morphology of a normal juvenile liver (H\&E). The hepatic parenchyma is composed of somewhat polyedric hepatocytes (h) with clear hepatocytes which should indicate good glycogen storage (Simpson, 1992). Many sinusoids branch from larger blood vessels like branches of the hepatic portal vein (hpv) and contain sparse erythrocytes (e). Normal hepatocytes have constant-shaped nuclei with well-individualized eu- and heterochromatin and concentric nucleoli. (B and C) Hepatic parenchyma of a fish in situ-exposed to sediments from site $C_{1}$ (the most metal-contaminated), in the laboratory, for 28 days (H\&E). (B) A necrotic (arrowheads) area is spreading around a branch of the hepatic portal triad ("piecemeal" necrosis). The necrotic tissue is invaded by erythrocytes, indicating haemorrhage. The bile ducts of the triad also show signs of regression/necrosis (rd). Relatively small and sparse lipid vacuoles (lv) indicate moderate lipidosis. (C) The liver of this individual presented massive hepatocellular alteration and modest lipidosis. (ah) eosinophilic-altered hepatocyte; (lv) lipid vacuole; (m) melanomacrophages forming dense centres at a blood-swollen hepatic portal vein branch. (D) Detail of the liver of an in situ-exposed fish (site $C_{2}$, the most contaminated by organic xenobiotics) for 28-days (H\&E). Nuclear pleomorphisms such as pyknosis (pn) were commonly observed in cells near or at necrotic areas (n). A pleomorphic nucleus of undisclosed type (probably apoptotic) can also be observed (arrowhead), as well as a Kupfer cell with many phagosomes (arrow). (lv) indicates lipid vacuoles. (E) Liver of a field-exposed fish in site $C_{1}$ for 14 days exhibiting many large fat vacuoles (lv) and an early-stage necrotic focus ( $\mathrm{n}$ ) around blood vessel with erythrocytes intruding into the damaged tissue (arrowheads). An adjacent blood vessel (bv) shows pronounced swelling caused by an increase in blood cells during inflammation (H\&E). (F) Detail of the liver of a field-exposed fish (site $C_{1}$ ) for 28 days were a Kupfer cell is observed intruding into a necrotic area (n) from an adjacent blood vessel (arrow); (s) indicates sinusoids (Giemsa stain). (G-I) Eosinophilic bodies (hyaline degeneration) in the liver of animals exposed to the reference sediment for 28 days under laboratory conditions. (G) H\&E stain; (H) Sudan Black B stain, signalling positive for protein-bound lipids inside the bodies and (I) Coomassie Brilliant Blue stain for peptides with positive signal for peptide material inside eosinophilic bodies. (eb) eosinophilic bodies; (hn) hepatocyte nuclei; (lv) lipid ("fat") vacuoles of common lipidosis appearing as empty-like structures in paraffin-embedded samples.

$\mathrm{T}_{14}$ (Mann-Whitney $U, p<0.05$ ). Still, no statistical differences were found between fish exposed to sediments $C_{1}$ and $C_{2}$ for either case. At $T_{28}$, however, $I_{\mathrm{h}}$ for fish exposed to $C_{1}$, in the laboratory was significantly higher than $R$ and $C_{2}$ tests $(p<0.05)$ but no signif- 
Table 2

Summary of the histopathological traits (biomarkers) assessed in the livers of tested $S$. senegalensis and respective weights.

\begin{tabular}{lll}
\hline Reaction pattern & Histological alteration & Weight \\
\hline $\begin{array}{l}\text { 1. Circulatory } \\
\text { disturbances }\end{array}$ & Haemorrhage & $1^{\mathrm{a}}$ \\
2. Inflammatory response & $\begin{array}{l}\text { Profusion and dilation of blood vessels } \\
\text { Presence of melanomacrophages }\end{array}$ & $1^{\mathrm{b}}$ \\
& $1^{\mathrm{b}}$ & $2^{\mathrm{a}}$ \\
Kupfer cell infiltration & $2^{\mathrm{a}}$ \\
& Nuclear pleomorphisms & $3^{\mathrm{a}}$ \\
& Hepatocyte necrosis & $2^{\mathrm{a}}$ \\
4. Progressive & Bile duct regression/atrophy & $1^{\mathrm{b}}$ \\
& Lipidosis & $2^{\mathrm{b}}$ \\
& Intracellular eosinophilic bodies & $2^{\mathrm{b}}$
\end{tabular}

a Weights according to Bernet et al. (1999).

b Weights according to Costa et al. (2009b).

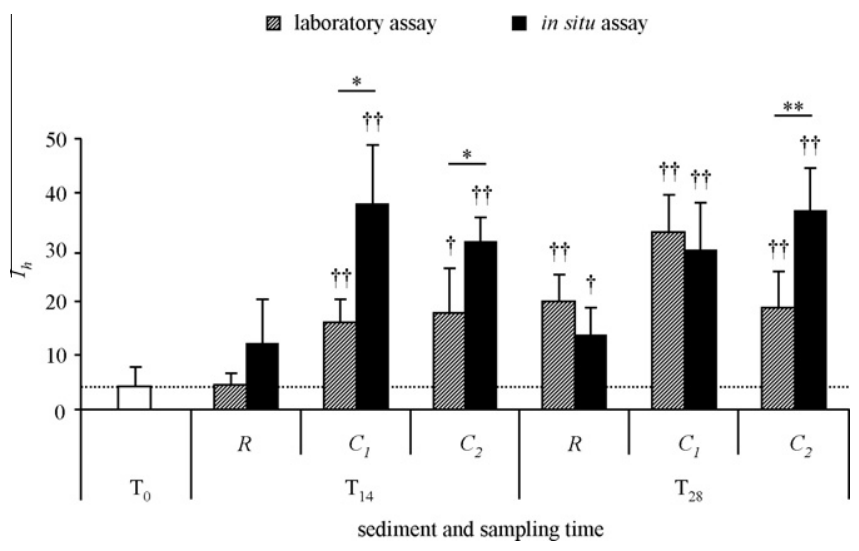

Fig. 3. Comparison of the average hepatic histopathological indice $\left(I_{\mathrm{h}}\right)$ between laboratory- and in situ-exposed fish to sediments from the reference $(R)$ and contaminated $\left(C_{1}\right.$ and $\left.C_{2}\right)$ sites at sampling times $\mathrm{T}_{0}, \mathrm{~T}_{14}$ and $\mathrm{T}_{28}$.* and $* *$ mean significant differences between laboratory and in situ-exposed fish, $p<0.05$ and $p<0.01$, respectively (Mann-Whitney $U$ test). $\dagger$ and $\dagger \dagger$ indicate significant differences to basal $I_{\mathrm{h}}$ at the beginning of the experiment ( $\mathrm{T}_{0}$ fish, dashed line), $p<0.05$ and $p<0.01$, respectively (Mann-Whitney $U$ test). Error bars indicate $95 \%$ confidence intervals.

icant differences where found between $R$ and $C_{2}$ tests. Regarding the in situ assay, exposures to the most contaminated sediments revealed higher indices than exposure to the reference sediment $(p<0.05)$ without, however, being statistically different between each other.

Upon analysis of the indices for each individual reaction pattern [2] it was observed that there was a differential contribution of the reaction pattern to the global indice $I_{\mathrm{h}}$ (Table 3 ). Regressive changes accounted for most variation of $C_{1}$ - and $C_{2}$-tested fish relatively to animals exposed to the reference sediment. On the other hand, it was observed that lipidosis (a progressive alteration) was more frequent and severe in field-exposed fish. Circulatory changes were highly variable but the frequency and severity of intra-hepatic haemorrhages depicted a tendency to increase in animals exposed to the two most contaminated sediments in both laboratory and field tests. With respect to inflammatory response, the differences between fish exposed to the reference sediment and those exposed to $C_{1}$ and $C_{2}$ were more notorious but laboratory-exposed fish only showed a significant increase in frequency and severity of these changes at $\mathrm{T}_{28}$.

Correlation-based cluster analysis on the individual indices for each histological change (weight $\times$ score) showed that some histopathological alterations were correlated (Fig. 4). Three unambigu-

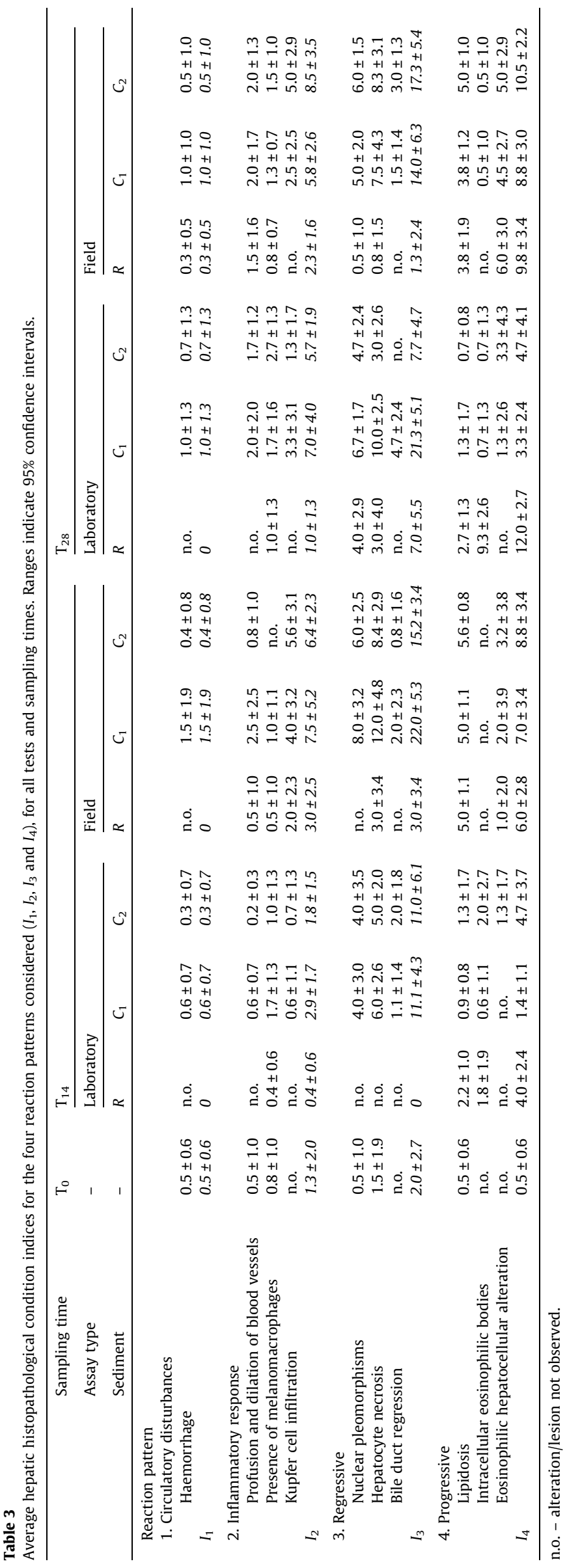




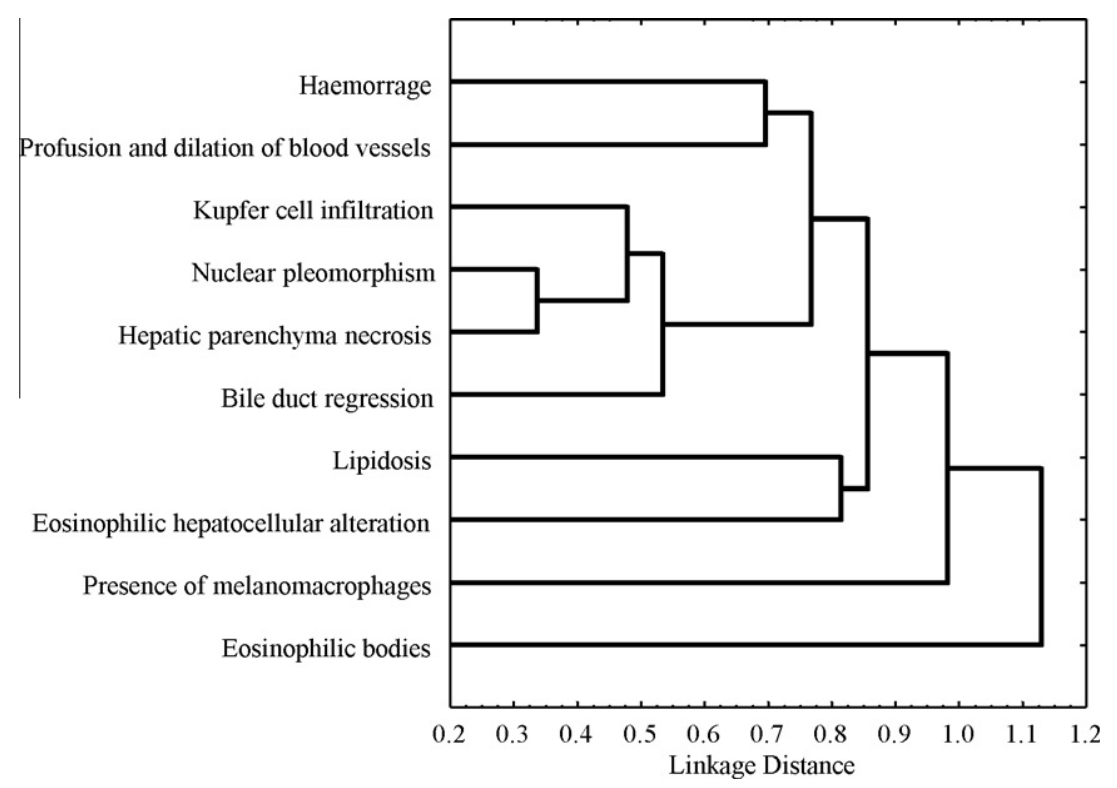

Fig. 4. Cluster analysis for all prospected histopathological biomarkers. Distances are based on the 1-Pearson correlation statistic $r$ between condition indices. Amalgamation was achieved through unweighted pair-group averages.

ous clusters were observed, the first comprising haemorrhage and blood vessel swelling; the second including Kupfer cell infiltration, nuclear pleomorphisms, hepatocyte necrosis and bile duct regression and the third joining lipidosis with hepatocellular alteration. Presence of melanomacrophages and eosinophilic bodies appeared as uncorrelated histopathological traits. Hepatocyte necrosis and nuclear pleomorphisms presented the strongest correlation.

From the discriminant analysis (Table 4) it was observed that at $\mathrm{T}_{14}$, the reaction patterns that contributed the most to differentiate laboratory- and field-tested animals were inflammatory response and regressive changes, with the latest being the most significant reaction pattern at $T_{28}$. The reaction patterns of inflammation and progressive changes contributes the most to discriminate between laboratory-tested animals collected at $\mathrm{T}_{14}$ from those collected at $T_{28}$. Conversely, no reaction patterns could significantly discriminate between field-tested fish collected at $\mathrm{T}_{14}$ and $\mathrm{T}_{28}$. Overall, only the discrimination between $\mathrm{T}_{14}$ and $\mathrm{T}_{28}$ for laboratory-exposed fish and between laboratory- and field-tested fish sampled at $\mathrm{T}_{14}$ were found to be significant (Wilk's $\lambda=0.51$, $p<0.01$ and Wilk's $\lambda=0.56, p<0.05$; respectively).

\section{Discussion and conclusions}

The present findings indicate that laboratory and field bioassays may yield histopathological observations that are consistent with the overall contamination levels of estuarine sediments. However, it has also been demonstrated that there are significant differences between the two types of exposure regarding not only the increase in the global hepatic condition indice $I_{\mathrm{h}}$ comparatively to the reference exposure but also the relative importance of each surveyed reaction pattern. Differences between laboratory-tested and fieldcollected or exposed organisms have already been reported by other authors and recognized as an important constraint when identifying the real toxicopathic effects of xenobiotics (see, for instance, Vethaak et al., 1996; Hatch and Burton, 1999). These differences are likely caused by (i) assay-induced factors that enhanced contaminant bioavailability in the laboratory assays and (ii) unmanageable environmental variables that affected field-tested animals such as access to food.

With the exception of fish exposed to sediment $C_{2}$, in the laboratory, for 28 days, $I_{\mathrm{h}}$ levels were significantly higher in fish exposed to the two contaminated sediments, $C_{1}$ and $C_{2}$, when compared to the reference test and $\mathrm{T}_{0}$ individuals. However, no differences were found between $C_{1}$ and $C_{2}$ exposures in the field assays and, as to the laboratory experiment, only at $T_{28}$ fish exposed to $C_{2}$ revealed greater histopathological changes comparing to $C_{1}$. This can be partially explained by the fact that, unexpectedly, the levels of metallic and organic contaminants in the two most contaminated sediments, $C_{1}$ and $C_{2}$, were found more similar than in previous research (with sediments collected at proximate locations), mostly due to an increase in PAH contamination in sed-

Table 4

Discriminant analysis results taking assay type and sampling time as grouping variables (factors). Lowest Wilk's $\lambda$ statistic was employed to assess best model. The most significant variables within a model were determined by F-tests following sequential addition of variables. The models' dependent variable is the hepatic histopathological condition indice $\left(I_{\mathrm{h}}\right)$ obtained for each individual.

\begin{tabular}{|c|c|c|c|c|c|c|c|c|c|c|}
\hline & & \multirow{3}{*}{$\begin{array}{l}\text { Model } \\
\text { Wilk's } \lambda\end{array}$} & \multicolumn{8}{|l|}{ Variables } \\
\hline & & & \multicolumn{2}{|l|}{$\underline{I_{1}}$} & \multicolumn{2}{|l|}{$\underline{I_{2}}$} & \multicolumn{2}{|l|}{$\underline{I_{3}}$} & \multicolumn{2}{|l|}{$\underline{I_{4}}$} \\
\hline & & & Wilk's $\lambda$ & $p$ to remove & Wilk's $\lambda$ & $p$ to remove & Wilk's $\lambda$ & $p$ to remove & Wilk's $\lambda$ & $p$ to remove \\
\hline Factors to discriminate & Case & & & & & & & & & \\
\hline \multirow[t]{2}{*}{ Assay type: laboratory $\times$ in situ } & $\mathrm{T}_{14}$ & $0.56^{*}$ & 0.57 & 0.68 & 0.67 & 0.02 & 0.56 & 0.73 & 0.64 & 0.05 \\
\hline & $\mathrm{T}_{28}$ & 0.86 & 0.86 & 0.93 & 0.90 & 0.18 & 0.87 & 0.53 & 0.97 & 0.04 \\
\hline \multirow{2}{*}{ Sampling time: $T_{14} \times T_{28}$} & Laboratory & $0.51^{* *}$ & 0.52 & 0.60 & 0.74 & 0.00 & 0.52 & 0.37 & 0.79 & 0.00 \\
\hline & In situ & 0.90 & 0.91 & 0.60 & 0.90 & 0.96 & 0.91 & 0.45 & 0.97 & 0.12 \\
\hline
\end{tabular}

"** Significance level for the model, $p<0.05$ or $p<0.01$, respectively (F-test). 
iment $C_{1}$ and metals in $C_{2}$ (see Costa et al., 2009a). Nevertheless, with respect to the levels of toxicants, the sediments tested during the present work can be considered clean $(R)$ to moderately contaminated $\left(C_{1}\right.$ and $\left.C_{2}\right)$. Another factor that contributed to the dilution of the differences between tests $C_{1}$ and $C_{2}$ concerns the interaction between metallic and organic xenobiotics, an issue reported in previous research (Costa et al., 2009b), especially the antagonistic effects between metals and PAHs.

Polycyclic aromatic hydrocarbons are insoluble compounds whose elimination depends on the inactivation by the cytochrome P450 (CYP) monooxygenase complex, producing more soluble compounds like the highly genotoxic diol-epoxides and reactive oxygen species (ROS) as by-products (see Miller and Ramos, 2001 for a review). Besides the importance of the non-metallic micronutrient selenium to anti-oxidant defences (Martínez-Álvares et al., 2005), best represented in sediment $C_{1}$, metals may have reduced immediate $\mathrm{PAH}$ toxicity by impairing CYP induction and activity (e.g. Vakharia et al., 2001), causing a "delay" in the severity of histopathological damage in fish exposed to the most contaminated sediment $\left(C_{1}\right)$. If this "delay" in the effects has, indeed, occurred, that might contribute to explain the very significant increase in the $I_{\mathrm{h}}$ values, for fish exposed in the laboratory to the sediment $C_{1}$, between $T_{14}$ and $T_{28}$, (inclusively, very significantly increasing over $C_{2}$-tested fish), which was not observed in field tests. It should be noted that the existence of severe regressive lesions account the most for the higher $I_{\mathrm{h}}$ of $C_{1}$-exposed fish for 28 days compared to test $C_{2}$, especially necrosis and bile duct damage. This may indicate that antagonistic effects between the different types of contaminants may mask the true toxicopathic effects at early stages of exposure without, however, contributing to a real attenuation. Regarding in situ exposures, if the physico-chemical characteristics of the sediment did not so drastically change, it can be inferred that contaminants may have remained trapped in the sediments meaning that the full toxicological potential was not triggered. As a consequence, this antagonistic effect between element and organic contaminants was not so pronounced, leading only to a more marginal increase in the global histopathological indice $I_{\mathrm{h}}$ of $C_{1}$-exposed fish relatively to $C_{2}$. To this may be added the fact that the levels of metallic and organic contaminants in both sediments were somewhat more resembled than expected and that the two classes of pollutants have different behaviours regarding their release from sediments. Organic compounds, especially PAHs, which are hydrophobic and essentially adsorbed to the sediment's fine particles and organic matter, are more difficultly released to the water column under stable conditions of the upper layers of sediment but disturbance events combined with low Eh may favour their release, increasing bioavailability (refer to Eggleton and Thomas, 2004, for a review). It is likely that laboratory sediments favoured contaminant bioavailability in tests $C_{1}$ and $C_{2}$ through a combination of sediment handling and animal-driven resuspension with high anoxia, TOM and FF. This enhanced bioavailability may have amplified antagonistic interaction effects in laboratorytested fish (Costa et al., 2009b). Although this interaction might also have affected fish exposed to sediment $C_{2}$, its effects were likely more pronounced in fish exposed to sediment $C_{1}$, with higher levels of metals.

The histopathological changes observed appear to be unspecific to a particular set of contaminants, regardless of reaction pattern, but they reflect the global aspects of sediment contamination. Inflammation and circulatory disturbances (reaction patterns 1 and 2, respectively) were observed to be very variable, but follow the overall histopathological condition of tested fish. Interestingly, Kupfer cell intrusion (more notorious in field-exposed fish) was found to be well correlated to more severe alterations such has hepatocyte necrosis. Besides phagocytosis, Kupfer cells are known to have a role in intercellular communication in the presence of a xenobiotic challenge, e.g., by releasing tumour necrosis factor, TNF (Milosevic et al., 1999), which contributes to explain the link between infiltration and strong parenchyma damage. The activation of this liver-specific response has been found, for instance, to be triggered by metals and an organochlorine pesticide, lindane, with evidence for an agonist interaction (Junge et al., 2001), which contributes to the assumption that Kupfer cell infiltration is nonspecific to xenobiotic types. Intrusion of melanomacrophages, on the other hand, was very variable and was not found clearly correlated with any other histological change, although a link was observed between melanomacrophage intrusion and agglomeration with the sediment contamination levels. Interestingly, Miranda et al. (2008) found histological evidence that supports the occurrence of immunosuppression in feral teleosts exposed to environmental organochlorines, leading to reduced presence of melanomacrophages. Conversely, some authors found the presence of dense melanomacrophage aggregates in fish liver and other organs a good biomarker of general exposure to environmental contaminants (e.g. Oliveira Ribeiro et al., 2005). It is probable that intrusion of these defence cells is variable and modulated by factors other than the degree of damage in the liver.

Hepatocellular eosinophilic alteration and lipidosis were more disseminated in field-tested fish. Although the occurrence of both progressive changes is well documented in literature, the exact causes and consequences of both are not yet fully understood. Although eosinophilic or basophilic hepatocellular alterations are regarded as pre-neoplasic, these histopathological traits are considered to be reversible. Its exact biological consequence is unclear but Koehler and co-workers (2004); for instance, found that the metabolic activity is upregulated in pre-neoplasic eosinophilic hepatocytes in feral flounders from PCB-contaminated sites. With respect to lipidosis, although some authors suggested that fact vacuolation is a response mechanism to store liposoluble xenobiotics (such as PAHs and organochlorines) or their metabolites (e.g. Köhler, 1990; Biagianti-Risbourg et al., 1995) this feature is more commonly regarded as an unspecific alteration with multiple potential causes. Interestingly, our previous work with S. senegalensis exposed to sediments from the proximate locations already reported a correlation between the presence of hepatocellular alteration and lipidosis and a link between these alterations and sediment contamination (Costa et al., 2009b). Similarly, the level of dissemination of both alterations is better linked to contamination in the laboratory assay than in the field experiment (where even fish exposed to the reference sediment presented diffuse forms of both), revealing that these changes may be triggered by undisclosed environmental factors. Fatty livers are common in aquaculturebrooded fish and may depend on diet. Tucker et al. (1997) found no short-term adverse effects of this condition on the livers of farmed fish, however, other authors discussed that fatty livers may have their energy production and anti-oxidant responses impaired (Vendemiale et al., 2001). Morales et al. (2004) found that, although reversibly, food deprivation causes oxidative stress and increases lipid peroxidation in teleost livers. It is possible that environmental factors such as access to food are, at least partially, responsible for the dissemination of fatty livers in field-exposed fish to the reference sediment, which might also account for some of the observed mortality. In fact, whereas in fish tested in sediments $C_{1}$ and $C_{2}$ the remains of small bivalves and gastropods were found in the digestive tracts, fish tested in sediment $R$ frequently presented no signs of recent meals. This may be linked to the fact that the reference area has higher hydrodynamics, causing the upper layer of sediment to be more labile thus making access to preys more difficult. The animals may thus have had their fat metabolism altered and, as a consequence, be more prone to acquire hepatocellular dysfunctions as a result of increased oxidative stress and weakened anti-oxidative responses (see Sánchez-Pérez 
et al., 2005). Overall, the combined geophysical characteristics of the reference area are likely to have had a considerable, yet unmanageable, effect of the health status of the animals, whether by impairing access to food or some sort of physical stress. Fish exposed to the two contaminated sediments, on the other hand, may have suffered from lipidosis and eosinophilic alteration mostly as a result of exposure to xenobiotics, from metals (Arellano et al., 1999; Shaw and Handy, 2006; Giari et al., 2007), organic toxicants such as organochlorines (Miranda et al., 2008), or sediment-based mixtures (Oliveira Ribeiro et al., 2005; Costa et al., 2009b). Lipidosis has even been found a persistent trait in fish recovering from $\mathrm{Cu}$ exposure (Shaw and Handy, 2006), which may premeditate caution when interpreting this biomarker.

Intraplasmatic eosinophilic bodies were observed to contain protein and protein-bound lipids, which is in accordance with the observations by Koller (1973), who first observed tat these inclusions are constituted by amorphous peptidic and lipidic material, consistent with enlarged lysosomes. The same author ruled out a pathogenic origin to hyaline degeneration. The absence of defence cells other than macrophages (namely lymphocytes) indicates that this alteration was unlikely caused by infectious agents. Unlike previous research, when eosinophilic bodies (occasionally termed hyaline degeneration) were found in conjunction with hepatic necrosis and linked to the exposure to organic xenobiotics (Costa et al., 2009b), these inclusions were found to be unrelated to severe regressive changes. Accordingly, other authors reported the existence of multiple small eosinophilic inclusions in the liver of fish exposed to metals without, however, coexistence with severe structural damage (Van Dyk et al., 2007). Similarly, biomedical research has reported the existence of these inclusions in human neoplasic livers but no direct link with patient survival was found (Chedid et al., 1999). It is possible that hyaline degeneration is an unspecific alteration with multiple, yet unknown, causes, as suggested by previous work from our group (Costa et al., 2009b). The presence of multiple small eosinophilic structures inside hepatocytes of fish exposed to the contaminated sediments resemble the Mallory-Denk bodies described for mammals, which are known to have a very ubiquitous origin (see Strnad et al., 2008). Although hyaline degeneration can be found together with other severe lesions, it appears that its actual significance may be masked by multiple confounding factors which implicates that further research is yet needed before the presence of eosinophilic bodies in hepatocytes can be regarded as a potential histopathological biomarker of environmental contamination on its own.

Histopathological biomarkers proved to be solid tools to monitor sediment-bound contaminants in estuaries if integrated through a semi-quantitative arrangement of condition indices that take into consideration not just the degree of dissemination but also the biological importance ("weight") of the lesion or alteration. The individual indices were proved to be highly advantageous when analysing the data through, e.g., multivariate statistics, yet another asset demonstrated elsewhere (Costa et al., $2009 \mathrm{~b}$ ). Provided that the proper weights are attributed and that possible confounding factors are taken into consideration, it appears to be advantageous to assess as many histopathological traits possible in order to cope with inter-individual variation, the unspecificity of lesions to a particular class of contaminants and the fact that some reaction patterns may be better indicators of the global health status of the fish than others as did regressive changes in the present study. It is also important to notice that histopathological lesions are likely to appear, in laboratory and field bioassays, even in "control" or "reference" organisms, so a comparative approach is compulsory, as well as the choice of an adequate reference. Both laboratory and field assays could provide results that could correlate to the global sediment contamination, a result that can relate to previous findings when histopathology was em- ployed in biomonitoring procedures (Riba et al., 2005). These results indicate that semi-quantitative histopathological analyses in fish are an adequate approach to take part of ecological risk assessment strategies, regardless of the assay methodology. However, field assays provided clearer comparisons between contaminated and clean sites even though unknown environmental factors caused some degree of experimental noise. Also, the integration of multiple histopathological biomarkers or potential biomarkers into combined indices that consider both the biological importance of the change as well as its degree of dissemination allows surpassing some of the inter-individual variation and assay or environment-induced variability, in spite of the non-specificity of lesions to a toxicant or class of toxicants.

\section{Acknowledgements}

The present research was approved by the Portuguese Science and Technology Foundation (FCT) and POCTI (Programa Operacional Ciência, Tecnologia e Inovação, research project ref. POCTI/AMB $57281 / 104$ ) and financed by FEDER (European Fund for Regional Development). P.M. Costa is supported by a FCT PhD grant (SFRH/BD/28465/2006). For their support, the authors would like to thank APSS (Administração dos Portos de Setúbal e Sesimbra, SA) and J. Raimundo, V. Branco, R. Cesário and P. Pousão (IPIMAR-INRB).

\section{References}

Arellano, J.M., Storch, V., Sarasquete, C., 1999. Histological changes and copper accumulation in liver and gills of the Senegalese sole, Solea senegalensis. Ecotoxicol. Environ. Safety 44, 62-72.

Au, D.W.T. 2004. The application of histo-cytopathological biomarkers in marine pollution monitoring: a review. Mar. Pollut. Bull. 48, 817-834.

Bernet, D., Schmidt, H., Meier, W., Burkhardt-Holm, P., Wahli, T., 1999. Histopathology in fish: a proposal for a protocol to assess aquatic pollution. J. Fish Dis. 22, 25-34.

Biagianti-Risbourg, S., Pairault, C., Vernet, G., Boulekbache, H., 1995. Effect of lindane on the ultrastructure of the liver of the rainbow trout, Oncorhynchus mykiss, sac-fry. Chemosphere 33, 2065-2079.

Bronner, R., 1975. Simultaneous demonstration of lipids and starch in plant tissues. Biotech. Histochem. 50, 1-4.

Cabral, H.N., 2000. Comparative feeding ecology of sympatric Solea solea and S. senegalensis, within the nursery areas of the Tagus estuary, Portugal. J. Fish. Biol. $57,1550-1562$

Caeiro, S., Costa, M.H., Ramos, T.B., Fernandes, F., Silveira, N., Coimbra, A., Medeiros, G., Painho, M., 2005. Assessing heavy metal contamination in Sado estuary sediment: an index analysis approach. Ecol. Indic. 5, 151-169.

Caetano, M., Fonseca, N., Cesário, R., Vale, C., 2007. Mobility of Pb in salt marshes recorded by total content and stable isotopic signature. Sci. Total Environ. 380 84-92.

Chapman, P.M., Hollert, H., 2006. Should the sediment quality triad become a tetrad, a pentad or possibly even a hexad? J. Soil Sed. 6, 4-8.

Chedid, A., Ryan, L.M., Dayal, Y., Wolf, B.C., Falkson, G., 1999. Morphology and other prognostic factors of hepatocellular carcinoma. Arch. Pathol. Lab. Med. 123 524-528.

Costa, P.M. Lobo, J., Caeiro, S., Martins, M., Ferreira, A.M., Caetano, M., Vale, C. DelValls, T.A., Costa, M.H., 2008. Genotoxic damage in Solea senegalensis exposed to sediments from the Sado estuary (Portugal): effects of metallic and organic contaminants. Mutat. Res. 654, 29-37.

Costa, P.M., Caeiro, S., Diniz, M., Lobo, J., Martins, M., Ferreira, A.M., Caetano, M. Vale, C., DelValls, T.A., Costa, M.H., 2009a. Biochemical endpoints on juvenile Solea senegalensis exposed to estuarine sediments: the effects of contaminant mixtures on metallothionein and CYP1A induction. Ecotoxicology 18, 9881000 .

Costa, P.M., Diniz, M.S., Caeiro, S., Lobo, J., Martins, M., Ferreira, A.M., Caetano, M. Vale, C., DelValls, T.A., Costa, M.H., 2009b. Histological biomarkers in liver and gills of juvenile Solea senegalensis exposed to contaminated estuarine sediments: a weighted indices approach. Aquat. Toxicol. 92, 202-212.

Costa, P.M., Caeiro, S., Diniz, M.S., Lobo, J., Martins, M., Ferreira, A.M., Caetano, M. Vale, C., DelValls, T.A., Costa, M.H., 2010. A description of chloride cell and kidney tubule alterations in the flatfish Solea senegalensis exposed to moderately contaminated sediments from the Sado estuary (Portugal). J. Sea Res. 64, 465-472.

Costley, C.T., Mossop, K.F., Dean, J.R., Garden, L.M., Marshall, J., Carroll, J., 2000 Determination of mercury in environmental and biological samples using pyrolysis atomic adsorption spectrometry with gold amalgamation. Anal. Chim. Acta $405,179-183$. 
DelValls, T.A., Blasco, J., Sarasquete, M.C., Forja, J.M., Gomez-Parra, A., 1998. Evaluation of heavy metal sediment toxicity in littoral ecosystems using juveniles of the fish Sparus aurata. Ecotoxicol. Environ. Safety 41, 157-167.

Eggleton, J., Thomas, K.V., 2004. A review of factors affecting the release and bioavailability of contaminants during sediment disturbance events. Environ. Int. 30, 973-980.

Ferreira, A.M., Martins, M., Vale, C., 2003. Influence of diffuse sources on levels and distribution of polychlorinated biphenyls in the Guadiana River estuary, Portugal. Mar. Chem. 89, 175-184.

Fisher, D.B., 1968. Protein staining of ribboned epon sections for light microscopy. Histochem. Cell Biol. 16, 92-96.

Giari, L., Manera, M., Simoni, E., Dezfuli, B.S., 2007. Cellular alterations in different organs of European sea bass Dicentrarchus labrax (L.) exposed to cadmium. Chemosphere 67, 1171-1181.

Hatch, A.C., Burton Jr., G.A., 1999. Sediment toxicity and storm water runoff in a contaminated receiving system: consideration of different bioassays in the laboratory and field. Chemosphere 39, 1001-1017.

Junge, B., Carrion, Y., Bosco, C., Galleano, M., Puntarulo, S., Tapia, G., Videla, L.A., 2001. Effects of iron overload and lindane intoxication in relation to oxidative stress, Kupffer cell function, and liver injury in the rat. Toxicol. Appl. Pharmacol. $170,23-28$.

Kiernan, J.A., 2008. Histological and Histochemical Methods. Theory and Practice, fourth ed. Scion Publishing Ltd., Bloxham.

Koehler, A., 2004. The gender-specific risk to liver toxicity and cancer of flounder (Platichthys flesus (L.)) at the German Wadden Sea coast. Aquat. Toxicol. 70, 257-276.

Koehler, A., Alpermann, T., Lauritzen, B., van Noorden, J.F., 2004. Clonal xenobiotic resistance during pollution-induced toxic injury and hepatocellular carcinogenesis in liver of female flounder (Platichthys flesus (L.)). Acta Histochem. 106, 155-170.

Köhler, A., 1990. Identification of contaminant-induced cellular and subcellular lesions in the liver of flounder (Platichthys flesus L.) caught at differently polluted estuaries. Aquat. Toxicol. 15, 271-294.

Koller, L.D., 1973. A note on eosinophilic cytoplasmatic bodies in the liver of a rabbit. Vet. Pat. 10, 295-298.

Lang, L., Wosniok, W., Baršienè, Broeg, K., Kopecka, J., Parkkonen, J., 2006. Liver histopathology in Baltic flounder (Platichthys flesus) as indicator of biological effects of contaminants. Mar. Pollut. Bull. 53, 488-496.

Martínez-Álvares, R.M., Morales, A.E., Sanz, A., 2005. Anti-oxidant defenses in fish: biotic and abiotic factors. Rev. Fish Biol. Fish. 15, 75-88.

Martins, M., Ferreira, A.M., Vale, C., 2008. The influence of Sarcocornia fruticosa on retention of PAHs in salt marshes sediments (Sado estuary, Portugal). Chemosphere 71, 1599-1606.

Martoja, R., Martoja, M., 1967. Initiation aux Techniques de l'Histologie Animal. Masson \& Cie, Paris.

Miller, K.P., Ramos, K.S., 2001. Impact of cellular metabolism on the biological effects of benzo[a]pyrene and related hydrocarbons. Drug. Metab. Rev. 33, 1-35.

Milosevic, N., Shawalder, H., Maier, P., 1999. Kupffer cell-mediated differential down-regulation of cytochrome P450 metabolism in rat hepatocytes. Eur. J. Pharmacol. 368, 75-87.

Miranda, A.L., Roche, H., Randi, M.A., Menezes, M.L., Ribeiro, C.A., 2008. Bioaccumulation of chlorinated pesticides and PCBs in the tropical freshwater fish Hoplias malabaricus: histopathological, physiological, and immunological findings. Environ. Int. 34, 939-949.

Morales, A.E., Pérez-Jiménez, A., Hidalgo, M.C., Abellán, E., Cardenete, G., 2004. Oxidative stress and antioxidant defenses after prolonged starvation in Dentex dentex liver. Comp. Biochem. Physiol. C 139, 153-161.

Myers, M.S., Johnson, L.L., Hom, T., Collier, T.K., Stein, J.E., Varanasi, U., 1998. Toxicopathic hepatic lesions in subadult English sole (Pleuronectes vetulus) from Puget sound, Washington, USA: relationships with other biomarkers of contaminant exposure. Mar. Environ. Res. 45, 47-67.
Neuparth, T., Correia, A.D., Costa, F.O., Lima, G., Costa, M.H., 2005. Multi-level assessment of chronic toxicity of estuarine sediments with the amphipod Gammarus locusta: I. Biochemical endpoints. Mar. Environ. Res. 60, 69-91.

Oliva, M., Garrido, M.C., Sales Márquez, D., González de Canales, M.L., 2009. Sublethal and lethal toxicity in juvenile Senegal sole (Solea senegalensis) exposed to copper: a preliminary toxicity range-finding test. Exp. Toxicol. Pathol. 61, 113-121.

Oliveira Ribeiro, C.A., Vollaire, Y., Sanchez-Chardi, A., Roche, H., 2005. Bioaccumulation and the effects of organochlorine pesticides, PAH and heavy metals in the eel (Anguilla anguilla) at the Camargue Nature Reserve. France Aquat. Toxicol. 74, 53-69.

Prieto-Álamo, M.-J., Abril, N., Osuna-Jiménez, I., Pueyo, C., 2009. Solea senegalensis genes corresponding to lipopolysaccharide and copper sulphate challenges: large-scale identification by suppression subtractive hybridization and absolute quantification of transcriptional profiles by real-time RT-PCR. Aquat. Toxicol. $91,312-319$.

Riba, I., Casado-Martínez, M.C., Blasco, J., DelValls, T.A., 2004. Bioavailability of heavy metals bound to sediments affected by a mining spill using Solea senegalensis and Scrobicularia plana. Mar. Environ. Res. 58, 395-399.

Riba, I., Blasco, J., Jiménez-Tenorio, N., González de Canales, M.L., DelValls, T.A., 2005. Heavy-metal bioavailability and effects: II. Histopathologybioaccumulation relationships caused by mining activities in the Gulf of Cádiz (SW, Spain). Chemosphere 58, 671-682.

Salamanca, M.J., Jínemez-Tenorio, N., Reguera, D.F., Morales-Caselles, C., DelValls, T.A., 2008. An early approach for the evaluation of repair processes in fish after exposure to sediment contaminated by an oil spill. J. Environ. Sci. Health A 43 , 1592-1597.

Sánchez-Pérez, Y., Carrasco-Legleu, C., García-Cuellar, C., Pérez-Carreón, J., Hernández-García, S., Salcido-Neyoy, M., Alemán-Lazarini, L., Villa-Treviño, S., 2005. Oxidative stress in carcinogenesis. Correlation between lipid peroxidation and induction of preneoplastic lesions in rat hepatocarcinogenesis. Cancer Lett. 217, 25-32.

Shaw, B.J., Handy, R.D., 2006. Dietary copper exposure and recovery in Nile Tilapia, Oreochromis niloticus. Aquat. Toxicol. 76, 111-121.

Simpson, M.G., 1992. Histopathological changes in the liver of dab (Limanda limanda) from a contamination gradient in the North Sea. Mar. Environ. Res. 34, 39-43.

Strnad, P., Zatloukal, K., Stumptner, C., Kulaksiz, H., Denk, H., 2008. Mallory-Denkbodies: lessons from keratin-containing hepatic inclusion bodies. Biochim. Biophys. Acta 1782, 764-774.

Tucker Jr., J.W., Lellis, W.A., Vermeer, G.K., Roberts Jr., D.E., Woodward, P.N., 1997. The effects of experimental starter diets with different levels of soybean or menhaden oil on red drum (Sciaenops ocellatus). Aquaculture 149, 323-339.

Vakharia, D.D., Liu, N., Pause, R., Fasco, M., Bessette, E., Zhang, Q.-Y., Kaminsky, L.S., 2001. Polycyclic aromatic hydrocarbon/metal mixtures: effect on PAH induction of CYP1A1 in human HEPG2 cells. Drug Metab. Dispos. 29, 999-1006.

Van Dyk, J.C., Pieterse, G.M., van Vuren, J.H.J., 2007. Histological changes in the liver of Oreochromis mossambicus (Cichlidae) after exposure to cadmium and zinc. Ecotoxicol. Environ. Safety 66, 432-440.

Vendemiale, G., Grattagliano, I., Caraceni, P., Caraccio, G., Domenicali, M., Dall'Agata, M., Trevisani, F., Guerrieri, F., Bernardi, M., Altomare, E., 2001. Mitochondrial oxidative injury and energy metabolism alteration in rat fatty liver: effect of the nutritional status. Hepatology 33, 808-815.

Vethaak, A.D., Jol, J.G., Meijboom, A., Eggens, M.L., Ap Rheinalt, T., Wester, P.W., van de Zande, T., Bergman, A., Dankers, N., Ariese, F., Baan, R.A., Everts, J.M., Opperhuizen, A., Marquenie, J.M., 1996. Skin and liver diseases induced in flounder (Platichthys flesus) after long-term exposure to contaminated sediments in large-scale mesocosms. Environ. Health Perspect. 104, 1218-1229.

Wester, P.M., van der Ven, L.T.M., Vethaak, A.D., Grinwis, G.C.M., Vos, J.G., 2002. Aquatic toxicology: opportunities for enhancement through histopathology. Environ. Toxicol. Pharmacol. 11, 289-295. 